\title{
Comparison Between Electropolishing Behavior of Copper and Mild Steel in the Presence of Lactic and Mandolic Acid
}

\author{
Fatma.M.Abouzeid \\ Chemistry Department, Faculty of Science, Alexandria University, Alexandria, Egypt \\ *E-mail: fatmaabouzeid44@ yahoo.com;
}

doi: $10.20964 / 2016.08 .20$

Received: 20 July 2015 / Accepted: 27 May 2016 / Published: 7 July 2015

\begin{abstract}
Addition of lactic and mandolic acid to electropolishing bath of copper and steel was examined using potentiodynamic polarization, weight loss method and scanning electron microscopic studies. Addition of different concentrations of lactic and mandolic acid gave a clear reduction in electropolishing rate. Scanning electron microscopic studies supplied the assenting proof of get better surface condition after addition of lactic and mandolic to electropolishing bath. The kinetic and activated parameters were computed for the dissolution process. Addition of lactic and mandolic acid to electropolishing bath made the solution appeared hopeful, a diverse development in the finish was noted where surface roughness , Ra decreases to a great extent by addition of lactic and mandolic acid.
\end{abstract}

Keywords: copper; steel; electropolishing; scanning electron microscopic; surface roughness

\section{FULL TEXT}

(C) 2016 The Authors. Published by ESG (www.electrochemsci.org). This article is an open access article distributed under the terms and conditions of the Creative Commons Attribution license (http://creativecommons.org/licenses/by/4.0/). 